\title{
The St. Petersburg paradox despite risk-seeking preferences: an experimental study
}

\author{
James C. Cox ${ }^{1}$ Eike B. Kroll ${ }^{2}$ - Marcel Lichters ${ }^{2}$ •

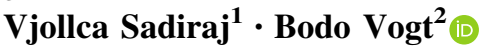

Received: 1 March 2018/Accepted: 9 October 2018/Published online: 26 October 2018

(C) The Author(s) 2018

\begin{abstract}
The St. Petersburg paradox is one of the oldest challenges of expected value theory. Thus far, explanations of the paradox aim at small probabilities being perceived as zero and the boundedness of utility of the outcome. This paper provides experimental results showing that neither diminishing marginal utility of the outcome nor perception of small probabilities can explain the paradox. We find that even in situations where subjects are risk-seeking, and zeroing-out small probabilities supports risk-taking, the St. Petersburg paradox exists. This indicates that the paradox cannot be resolved by the arguments advanced to date.
\end{abstract}

Keywords Decision-making under risk $\cdot$ St. Petersburg paradox $\cdot$ Riskaversion

\section{JEL Classification C91}

\section{Introduction}

The extent to which generations of researchers raise a certain issue is an indicator of its importance. One issue that researchers have repeatedly debated is a unified explanation for play of the St. Petersburg game, a paradox that has attracted researchers' interest for 300 years (Neugebauer 2010; Seidl 2013). In the original version of the St. Petersburg Game, a fair coin is tossed until it comes up heads for

Bodo Vogt

bodo.vogt@ovgu.de

1 Andrew Young School of Policy Studies, Georgia State University, 14 Marietta Street, Atlanta, GA 30303, USA

2 Otto-von-Guericke-University Magdeburg, Empirical Economics, Universitätsplatz 2, 39106 Magdeburg, Germany 
the first time. The game pays $2^{n}$ with $n$ indicating the number of tosses it takes for the first occurrence of heads. While the St. Petersburg game in its original version offers an infinite expected value, people are found to pay no more than $\$ 25$ for hypothetical offers to participate in the game, which may be regarded as irrational decision-making (Hacking 1980).

The paradox unfolds an immense importance in many diverse fields such as statistical decision analysis (Seidl 2013), econophysics (Takayasu 2010), business ethics (Shrader-Frechette 1985), economics (Rieger and Wang 2006; Samuelson 1960), psychology (Mishra 2014; Chechile and Barch 2013), and even evolutionary theory (Real 1980), in particular animals' foraging decisions studied in zoology (Real 1996). In the business research context, researchers routinely refer to the paradox when discussing and analyzing, for example, crashes of high-tech stocks (Székely and Richards 2004) and more generally the extent to which speculator psychology has attained an irrational bent at stock markets (Durand 1957), optimal contracting decisions (Mookherjee and Png 1989), optimal portfolio strategies (Rubinstein 2002), newsvendor order decisions (Wang et al. 2009), and loss aversion in consumer behavior (Camerer 2005).

Against this background, modeling play of the St. Petersburg game is essential in many fields. Although several explanations are proposed as solutions to this paradox, there is no general agreement on a unified model valid for different versions of the paradox. This article adds another layer of complexity to the topic, in that we present experimental evidence that shows similar play in finite St. Petersburg games with conventional positive prizes $\left(2^{n}\right)$ and negative prizes $\left(-2^{n}\right)$, as monetary payments but also in waiting time. These results are not compatible with loss aversion. Our data suggest that St. Petersburg games elicit similar choices that are invariant to the sign of prizes. As such, we hope our results will contribute to the ongoing discussion of the topic by providing new evidence on decisions about play of St. Petersburg games when prizes are negative, an issue that has been overlooked in the literature.

\section{Literature review and experiment overview}

Various researchers have provided explanations for the St. Petersburg paradox (e.g., Seidl 2013; Rieger and Wang 2006; Blavatskyy 2005), but with every explanation a new version of the initial game was constructed that brought back the puzzle (Samuelson 1977). Versions of the game have been constructed that challenge all currently popular theories of decision under risk (Cox and Sadiraj 2009).

Historically, the first explanation for the observed behavior was decreasing marginal utility of the outcome (Bernoulli 1954, originally published in 1738). However, for unbounded utilities, games can be constructed with prizes correcting for decreasing marginal utility and the paradox remains. ${ }^{1}$

\footnotetext{
${ }^{1}$ For log utility, replace payoffs $2^{n}$ with payoffs $\exp \left(2^{n}\right)$ and the paradox returns. More generally, for an unbounded utility, $u$ replace payoffs $2^{n}$ with payoffs given by the inverse function, $u^{-1}\left(2^{n}\right)$.
} 
Therefore, the focus shifted towards the credibility of "infinity" (i.e., no bounds on potential prizes, or on the number of coin flips). Limited time was introduced to bind the value of the St. Petersburg game (Brito 1975; Cowen and High 1988). In contrast, it was argued that the value of the lottery could in principle be unbounded but the offer to play the game is most probably not considered to be credible (Shapley 1977), explaining the decision patterns found in experimental studies. The most favored solution of the paradox, however, is that utility is bound since otherwise one can always create lotteries leading to counterintuitive solutions (Aumann 1977). But bounding utility substitutes one paradox for another: with bounded utility, an agent will exhibit implausible large-stakes risk-aversion (Cox and Sadiraj 2009).

To avoid infinity, the St. Petersburg Game was broken down into a series of finite games, but the paradox does not disappear (Samuelson 1960), questioning infinity as the underlying cause of the paradox. Other work argues that perception of small probabilities of large payoffs is the source of the paradox since sufficiently small probabilities are regarded as zero (Brito 1975) or small chances for large prizes create big risks for the agents (Allais 1952; Weirich 1984) who are willing to buy the game at a large price. In another approach on using probabilities as an explanation for the phenomenon, more recent work introduced a new weighting function for cumulative prospect theory, attempting to solve the problem of infinity (Blavatskyy 2005).

Experimental research has turned to a modified version of the question originally posed by Bernoulli: Is human choice behavior in St. Petersburg lotteries consistent with expected value theory in finite versions of the game that involve few coin tosses, $n$ ? Initial experiments followed the general idea that financial incentives provide subjects with an economic motivation for truthfully revealing ranking of available options (Camerer and Hogarth 1999). Thus, experiments based on enhanced designs (Cox et al. 2009; Neugebauer 2010) have used real-money payoffs and finite versions of the St. Petersburg game. Data from these experiments are inconsistent with risk-neutrality but consistent with risk-aversion for moderate $n$ ( $>5$ ) providing support for Bernoulli's general conclusion about risk-aversion (though not about a log specification) as the source of low willingness to pay for playing the game.

The present paper reports on two experiments that implement a modification of the St. Petersburg lotteries used in Cox et al. (2009), replacing positive prizes with negative ones. In Experiment 1, prizes in the St. Petersburg lotteries are $-2^{n}$ where $n$ is the number of coin tosses it takes to (first) turn up a head, which determines how much subjects get paid to play the game. That means, instead of offering subjects an opportunity to pay money for participating in a St. Petersburg game with positive prizes, this experiment provides subjects with an opportunity to receive money payment for accepting an offer to participate in a St. Petersburg game in which they can only lose money. Because this sign-mirror version of the St. Petersburg game offers stochastic losses, people may make different decisions depending on whether they are risk-loving or risk-averse over losses, a topic on which there is mixed evidence (e.g., Kahneman and Tversky 1979; Holt and Laury 2002, 2005; Åstebro et al. 2015). Previous research suggests that individuals tend to be risk-seeking 
when it comes to gambling involving the possibility to avert financial losses (e.g., Kahneman and Tversky 1984; Scholer et al. 2010; Rieger et al. 2015). Furthermore, if St. Petersburg play follows from sufficiently small probabilities being regarded as zero (Brito 1975) then we should expect larger willingness to play the game with negative prizes than with positive prizes.

For both the original version of the (finite) St. Petersburg lotteries taken from Cox et al. (2009) and the lotteries developed for this study, participants decide about tradeoffs between possible monetary gains and losses. In the $n=3$ version of the game, a subject who decides to participate pays $€ 2.75$ for sure and receives $€ 2$ (in the case the coin lands Head the first time), $€ 4$ in the event $\mathrm{T} \rightarrow \mathrm{H}$ (that is the first land is Tail and the second one is Head), $€ 8$ in the event $\mathrm{T} \rightarrow \mathrm{T} \rightarrow \mathrm{H}$ and $€ 0$ otherwise (that is, the event $\mathrm{T} \rightarrow \mathrm{T} \rightarrow \mathrm{T}$ ). The expected value of participating in the $n=3$ version of the finite St. Petersburg game is $€ 0.25$.

In total, $80 \%$ of the subjects decided to pay $€ 2.75$ to participate in the game (Cox et al. 2009). In the $n=3$ version of the sign-mirror St. Petersburg game, the game of interest in this paper, a subject who decides to participate gets paid $€ 3$ for sure but pays back $€ 2$ in the event $H, € 4$ in the event $\mathrm{T} \rightarrow \mathrm{H}, € 8$ in the event $\mathrm{T} \rightarrow \mathrm{T} \rightarrow \mathrm{H}$, and $€ 0$ in the case of event $\mathrm{T} \rightarrow \mathrm{T} \rightarrow \mathrm{T}$. (see Table 1 for $n=4$ and $n=9$ ). The expected value of participating in the $n=3$ sign-mirror version of the finite St. Petersburg game is $€ 0$. It is not clear how people will play this game in that the game participation is ex ante mixed (total payoff, which is prize plus payment for playing, can be positive or negative depending on the resolution of the risk),

Table 1 St. Petersburg lotteries for monetary losses (for $n=4$ and $n=9$ games)

\begin{tabular}{lllcl}
\hline $\begin{array}{l}\text { Head occurs the first } \\
\text { time at toss no. }\end{array}$ & $\begin{array}{l}\text { Event } \\
\text { probability }\end{array}$ & $\begin{array}{l}\text { Payment from } \\
\text { lotteries }(€)\end{array}$ & $\begin{array}{l}\text { Total payoff including } \\
\text { participation fee }(€)\end{array}$ & $\begin{array}{l}\text { Total payoff in case } \\
\text { of rejection }(€)\end{array}$ \\
\hline$n=4$ & & & & \\
Not at all & 0.0625 & 0 & 2 & 0 \\
1 & 0.5 & -2 & 0 & 0 \\
2 & 0.25 & -4 & -4 & 0 \\
3 & 0.125 & -8 & -12 & 0 \\
4 & 0.0625 & -16 & & 0 \\
$n=9$ & & & 9 & 0 \\
Not at all & 0.0019531 & 0 & 5 & 0 \\
1 & 0.5 & -2 & -4 & 0 \\
2 & 0.25 & -4 & -8 & 0 \\
3 & 0.125 & -8 & -23 & 0 \\
4 & 0.0625 & -16 & -55 & 0 \\
5 & 0.03125 & -32 & -119 & 0 \\
6 & 0.015625 & -64 & -247 & 0 \\
7 & 0.0078125 & -128 & -503 & 0 \\
8 & 0.0039062 & -256 & -512 &
\end{tabular}


whereas the prizes that the game offers are all negative. Risk-aversion, by definition, implies rejection of the St. Petersburg game with negative prizes, $S_{n}$ for all $n$ as the expected value of participation is zero. Furthermore, with expected utility, riskaversion implies that the likelihood of rejecting St. Petersburg game increases with $n .^{2}$ This is consistent with the pattern observed in Cox et al. (2009) (but also in data from the new experiments reported in this paper). On the other hand, with loss

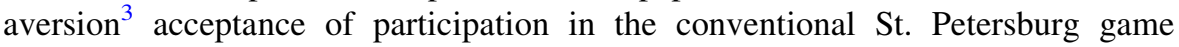
implies rejection of its sign-mirror St. Petersburg game.

Because the (prize plus participation payment) domain of participation in a St. Petersburg game (with positive or negative prizes) is mixed, we conducted another experiment (Experiment 2), reported later in the paper, with same lotteries as in Experiment 1, but with the difference that negative money prizes are replaced by waiting times. Additionally, in another control treatment we elicited subjects' preferences for waiting times using Holt and Laury's (2005) procedure. Our subjects' choices revealed risk-seeking attitudes when choosing waiting times in the control treatment, which implies that our subjects accept the negative St. Petersburg games (as the expected value of participation and nonparticipation is 0). In Experiment 2, we also observe decisions on participation in St. Petersburg lotteries constructed from the domain of waiting times used in the control treatment.

Data from the experiments reported in this paper show that decisions on participating in St. Petersburg games are invariant to the sign of prizes. If risk attitudes over negative payoffs are risk-seeking (a common finding in the literature as well as in our risk elicitation control treatment in Experiment 2), then data from experiments in this paper challenge stability of risk attitudes over negative prizes. Thus, the present research re-emphasizes a fruitful field of future inquiry on risk attitudes in negative domains of payoffs.

\section{Experiment 1: the St. Petersburg game with monetary payments}

\subsection{Experimental design and procedure}

Fifteen students from a major German university from different fields of study participated in the experiment. Subjects were invited by email and were informed that the experiment would spread over 2 weeks and that real losses could result from participation, but the losses could be avoided by individuals' decisions. Subjects were also informed that, in the event that a participant realized a loss, she would have to pay it from her own money.

During the first meeting, the participants received a show-up fee of $€ 10$. The information from the invitation was read aloud to the subjects and, subsequently, the participants filled out a form stating they were fully aware of the information

\footnotetext{
${ }^{2}$ It is straightforward (available upon request), though tedious, to show that for all $n$ in our experiment, participation in $S_{n}$ is a mean-preserving spread of participation in $S_{n-1}$. Figure 3 in the "Appendix" provides a visualization for the case of St. Petersburg games with $n=3$ and $n=4$.

3 See the "Appendix" for a proof when the functional is linear in probabilities.
} 
provided by the experimenter and they agreed to pay any losses that might occur from participation in the experiment.

The actual experiment on decisions about St. Petersburg lotteries was performed during the second meeting, 2 weeks later, which minimizes the possibility of introducing a bias resulting from house-money effects (e.g., Rosenboim and Shavit 2012; Thaler and Johnson 1990). The experiment consisted of the same lotteries used in Cox et al. (2009) with the only difference being that all payoffs were multiplied by the factor -1 (i.e., a sign-mirrored version of a finite St. Petersburg original game). For a total of 9 lotteries, the participants could choose between participating in the lottery or not (see Table 1 for $n=4$ and $n=9$ ). The lotteries varied in the maximum number of coin tosses, $n$ with $n=1,2, \ldots, 9$. After the participants made their decisions for all of the 9 lotteries, for each participant one lottery was randomly chosen for realization.

A subject choosing to participate in a lottery, $S_{n}$ with maximum of $n$ tosses received $n$ euros. Then a coin was tossed until either a head occurred or the maximum number $(n)$ of tosses for that lottery was reached. If the coin turned up heads on the $i$ th $(i<n)$ toss, the participant was required to pay $€ 2 i$.

If the coin did not turn up heads on any of the $n$ tosses, the participant was not required to pay anything and her payoff remained at $n$ euros. Thus, potential payoffs from the game participation are $n, n-2, n-4, \ldots, n-2^{n}$ with probabilities $1 / 2^{n}, 1 / 2$, $1 / 4, \ldots, 1 / 2^{n}$. In case of a rejection, the subject receives no payment. The expected value of the St. Petersburg game, $S_{n}$ is $-n$, and therefore the expected value of participation is 0 . Risk-seeking individuals would prefer participation whereas riskaverse individuals would reject it. ${ }^{4}$

\subsection{Results of Experiment 1}

The analysis of the data from our version of the St. Petersburg lotteries is adapted from the procedures used in Cox et al. (2009) to make comparisons. The analysis focuses on the proportion of subjects rejecting the St. Petersburg lottery for the maximum number of coin tosses, $n$. For the original form of the St. Petersburg lotteries involving positive prizes, researchers (Cox et al. 2009; Neugebauer 2010) found that the proportion of subjects rejecting a lottery increased with increasing numbers of maximum tosses of the coin, which is consistent with risk-aversion because increasing $n$ increases the spread of payoffs while preserving the mean. We see the same pattern in the sign-mirror version of St. Petersburg game with negative prizes. Figure 1 shows choices for positive prizes (light grey bars) and negative prizes (dark grey bars). While the proportion of subjects rejecting the lotteries is higher on average with negative prizes, the pattern of increasing rejections appears in both games. Therefore, there is a pattern to be found when subjects make decisions about St. Petersburg lotteries that is robust to whether monetary prizes are

\footnotetext{
${ }^{4}$ For illustration purposes, in the "Appendix" Table 5, we provide valuations of game participation for the special case of S-shaped utility of outcomes with power 0.5. For this example, the utility of participation decreases in $n$ for positive St. Petersburg game but increases in $n$ for negative St. Petersburg game. Therefore, we expect opposite patterns of likelihood of rejections: increasing for positive prizes but decreasing for negative prizes.
} 


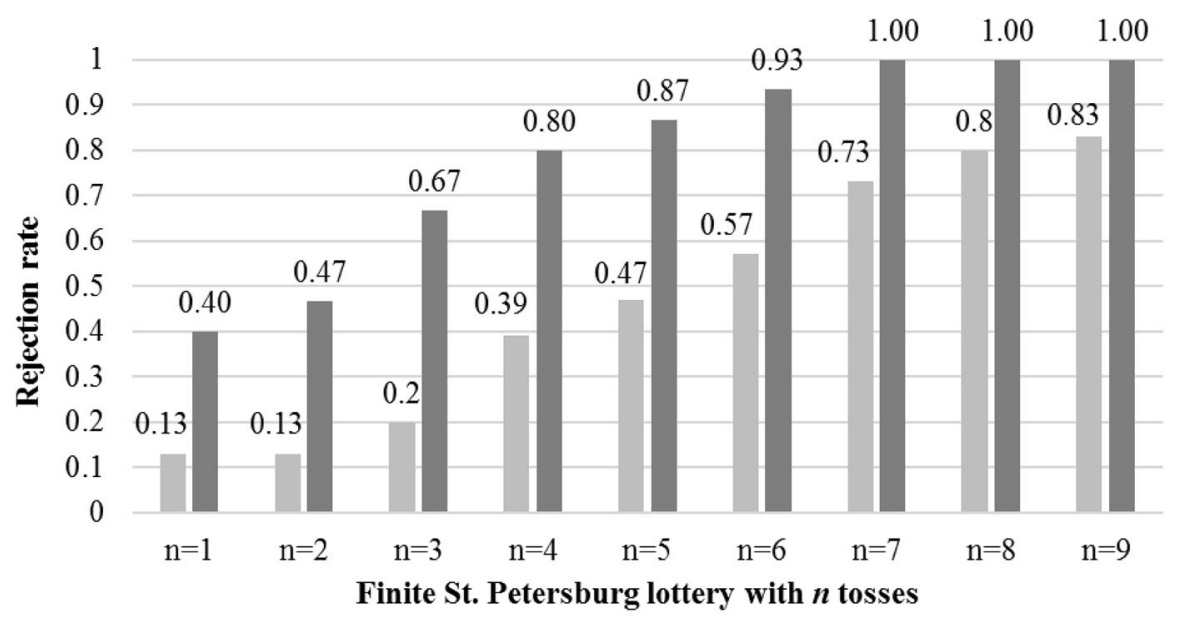

Cox et al. (2009) - monetary gains $\quad$ Study 1 - monetary losses

Fig. 1 Comparison of choices for positive or negative money prizes

positive or negative. Specifically, a significant correlation between the $n$ and the number of subjects rejecting to play $\left(r_{\text {Spearman }}=0.983, p<0.001\right)$ supports the notion of increasing rejection. Likewise, across $n$, the Pearson correlation between the rates of rejection reported in Cox et al. (2009) and Experiment 1 approaches 1 $\left(r_{\text {Pearson }}=0.941, p<0.001\right)$. Additionally, whereas risk-seeking behavior suggests an increasing willingness to play with increasing $n$, we were not able to observe this tendency for any of the individuals ( $p<0.001$ in a binomial test). With S-shaped utility and loss aversion, acceptance of positive St. Petersburg game implies rejection of negative St. Petersburg game (see "Appendix"). This is rejected by data from games with 1, 2, and 3 tosses. Acceptance rates in the positive St. Petersburg game are [0.87, 0.87, 0.8]; rejection rates in the negative St. Petersburg game are predicted to be larger but we observe [0.4, 0.47, 0.67].

\subsection{Discussion of Experiment 1}

The experiment's results highlight that St. Petersburg game play is invariant to gain vs. loss framing of lotteries. Experiment 1, however, involves two limitations. First, literature proposes that subjects sometimes might have a hard time believing that potential financial losses realized in experiments become relevant for them (e.g., Thaler and Johnson 1990). Likewise, a special type of subject tends to be more prone to participate in experiments with potential monetary losses, creating the possibility of a selection bias (Etchart-Vincent and l'Haridon 2011). Both aspects could be problematic for the internal validity of findings. ${ }^{5}$ Second, Experiment 1 drew on extant studies in assuming a risk-seeking tendency for gambles on financial

\footnotetext{
5 We would like to thank an anonymous reviewer for making this suggestion.
} 
losses. Therefore, we did not control whether our subjects' risk attitudes over losses were risk-seeking.

Experiment 2 addresses the aforementioned issues, while simultaneously operating with a larger sample. This second investigation substitutes waiting times for financial losses, which previously has been shown to provide an appropriate way for integration of realized losses in the context of prospect theory experiments (e.g., Abdellaoui and Kemel 2014). In addition, a control treatment provides data, which reveals that subjects are risk-seeking in gambles over waiting times.

\section{Experiment 2: waiting times}

\subsection{Experimental design and procedure}

The experiment was conducted with 86 students from different fields of study enrolled at the same major German university as in Experiment 1. The participants were randomly divided into three groups, with one eliciting risk preferences for waiting time (Treatment 1, 36 participants), and two groups playing St. Petersburg lotteries with different base waiting times (Treatment 2, 25 participants, $10 \mathrm{~min}$ and Treatment 3, 25 participants, $45 \mathrm{~min}$ ). All participants received a show-up fee of $€ 8$ before experiment instructions were handed out in the university's behavioral economics laboratory. Furthermore, it was made clear that there would be no other monetary rewards from participation in the experiment other than the consequences described in the experiment instructions. Unlike Experiment 1, the second experiment did not draw on two separate appointments because subjects are unlikely to integrate a monetary show-up fee with waiting times into one mental account (Abdellaoui and Kemel 2014).

\subsubsection{Risk preference for waiting time}

To elicit preferences over waiting time, participants were asked to choose between two lotteries in each of ten pairs of lotteries where "payoffs" were determined as waiting time. After choices were made, one choice pair was randomly selected for realization (e.g., Lichters et al. 2016). In the experiment, participants were told that their decisions would determine a waiting time in the laboratory. This waiting time started after all decisions were made and the chosen lotteries were played out. The participants spent this waiting time in a laboratory cabin without any communication devices or books.

The options were presented in a format similar to the one used in Holt and Laury (2005), where option A offered less risk but a higher minimum waiting time (with a waiting time of either 30 or $40 \mathrm{~min}$ ), and option B offered a higher risk but the chance of a much smaller waiting time (with a waiting time of either 5 or $60 \mathrm{~min}$ ). The probability of the favorable outcome was always the same in the two options but varied between 0.1 and 1.0 as shown in Table 2. Therefore, risk preferences for waiting time could be elicited for each participant by the row in which option B was chosen over A for the first time. If the switching point was in row four or earlier, the 
Table 2 Lottery choices determining waiting time

\begin{tabular}{lllll}
\hline No. & Option A & Option B & $\begin{array}{l}\text { Expected value of wait time } \\
\text { difference EV(A)-EV(B) }\end{array}$ & $\begin{array}{l}\text { Risk preferences } \\
\text { at switch from A to B }\end{array}$ \\
\hline 1 & $\{0.1,30,0.9,40\}$ & $\{0.1,5,0.9,60\}$ & -15.5 & Risk-seeking \\
2 & $\{0.2,30,0.8,40\}$ & $\{0.2,5,0.8,60\}$ & -11 & \\
3 & $\{0.3,30,0.7,40\}$ & $\{0.3,5,0.7,60\}$ & -6.5 & \\
4 & $\{0.4,30,0.6,40\}$ & $\{0.4,5,0.6,60\}$ & -2 & Risk-averse \\
5 & $\{0.5,30,0.5,40\}$ & $\{0.5,5,0.5,60\}$ & 2.5 & \\
6 & $\{0.6,30,0.4,40\}$ & $\{0.6,5,0.4,60\}$ & 7 & \\
7 & $\{0.7,30,0.3,40\}$ & $\{0.7,5,0.3,60\}$ & 11.5 & \\
8 & $\{0.8,30,0.2,40\}$ & $\{0.8,5,0.2,60\}$ & 16 & \\
9 & $\{0.9,30,0.1,40\}$ & $\{0.9,5,0.1,60\}$ & 20.5 & \\
10 & $\{1.0,30,0.0,40\}$ & $\{1.0,5,0.0,60\}$ & 25 & \\
\hline
\end{tabular}

choice pattern would indicate risk-seeking behavior, if it was in row five or later, the choice pattern would show risk-averse behavior.

After the choices were made, the experimenter drew a ball from a bingo cage with balls labeled from one to ten that determined which decision was selected. Then the outcome from the lottery the participant chose for the decision in the corresponding row was realized and the waiting time started.

\subsubsection{St. Petersburg game}

Participants in these treatments were offered a series of St. Petersburg lotteries. All subjects had a base waiting time (Treatment 2, $10 \mathrm{~min}$; Treatment 3, $45 \mathrm{~min}$ ) and were offered an opportunity to participate in a lottery where this waiting time could be reduced or increased depending on their decision and the outcome of the lottery. This lottery was designed analogously to the St. Petersburg lottery used in Experiment 1 (and Cox et al. 2009). For participation in the lottery, the waiting time was first reduced by $n$ minutes and subsequently a coin was tossed until a head occurred, with a maximum of $n$ tosses. If head occurred on the $i$ th toss, the waiting time was increased by $2^{i}$ minutes. Each participant was offered nine lotteries with only one decision being randomly selected for implementation, with the lotteries differing by the maximum number of tosses $n$. Table 3 shows potential waiting times for $n=9$ and base time $10 \mathrm{~min}$, here we describe the case for $n=3$. Suppose decision 3 was randomly selected for implementation. If the subject had chosen not to play the game then his waiting time was at the base waiting time of $10 \mathrm{~min}$ (or $45 \mathrm{~min}$ in the $45 \mathrm{~min}$ base-time condition).

If the subject had chosen to play the game, then the base waiting time was reduced by 3 min-7 (or 42) minutes. Then, a coin was tossed. If it came up heads at the first toss (an event with probability $1 / 2$ ), the waiting time was increased by 2-9 (or 44) min. If it came up heads at the second toss (an event with likelihood $1 / 4$ ), the 
Table 3 St. Petersburg lotteries for waiting time ( $n=9$, base time $10 \mathrm{~min}$ )

\begin{tabular}{lllll}
\hline $\begin{array}{l}\text { Head occurs } \\
\text { the first time } \\
\text { at toss no.: }\end{array}$ & $\begin{array}{l}\text { Event } \\
\text { probability }\end{array}$ & $\begin{array}{l}\text { St. Petersburg } \\
\text { prize [waiting } \\
\text { time in minutes] }\end{array}$ & $\begin{array}{l}\text { Total payoff including } \\
\text { participation fee of }-9 \\
\text { [waiting time in minutes] }\end{array}$ & $\begin{array}{l}\text { Total payoff for } \\
\text { rejecting to play } \\
\text { [waiting time in } \\
\text { minutes] }\end{array}$ \\
\hline Not at all & 0.0019531 & 0 & 1 & 10 \\
1 & 0.5 & 2 & 3 & 10 \\
2 & 0.25 & 4 & 5 & 10 \\
3 & 0.125 & 8 & 9 & 10 \\
4 & 0.0625 & 16 & 17 & 10 \\
5 & 0.03125 & 32 & 33 & 10 \\
6 & 0.015625 & 64 & 65 & 10 \\
7 & 0.0078125 & 128 & 129 & 10 \\
8 & 0.0039062 & 256 & 257 & 10 \\
9 & 0.0019531 & 512 & 513 & 10 \\
Expected & & 9 & 10 & \\
$\quad$ value & & & & \\
\hline
\end{tabular}

waiting time was increased by 4 min-11 (or 46) min. If it came up heads at the third toss, the waiting time was increased by $8 \mathrm{~min}-15$ (or 50) min. If the coin did not come up heads at any of the three tosses, the waiting time remained at 7 (or 42) min.

After the participants made their choices, the experimenter drew a ball from a bingo cage containing balls numbered from one through nine to select which game would be realized. Waiting time for all participants who chose not to play the selected game was the baseline time. For each participant who chose to play the game, the experimenter tossed the coin as described above and determined the actual waiting time. All participants spent their waiting time in a laboratory cabin without communication devices or other kinds of entertainment possibility. To control for scale and/or reference point effect (Farber 2008; Köszegi and Rabin 2007), we ran two treatments with different base waiting times of 10 and $45 \mathrm{~min}$.

\subsection{Results of Experiment 2}

\subsubsection{Risk preferences for waiting time}

As described above, subjects can be classified as risk-seeking or risk-averse for choices on waiting time by looking at the first row in which option B is chosen. In Table 2, it can be inferred from the differences in expected values that risk-seeking individuals would choose option B for the first time in row four or earlier, while the switching point from option A to option B would be in row five or later for riskaverse subjects. Table 4 reports the frequencies for rows in which subjects switched to option B: any subject who chooses option A in rows one through three and chooses option B in rows four through ten is noted in column four, while any subject 


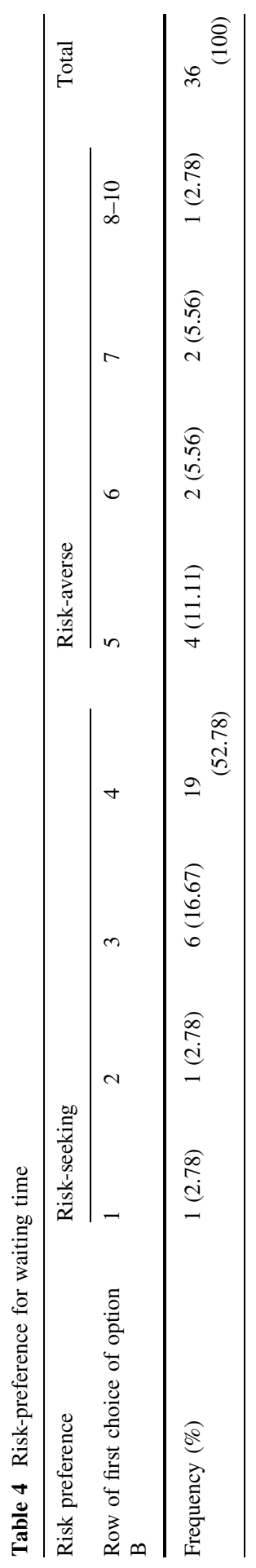




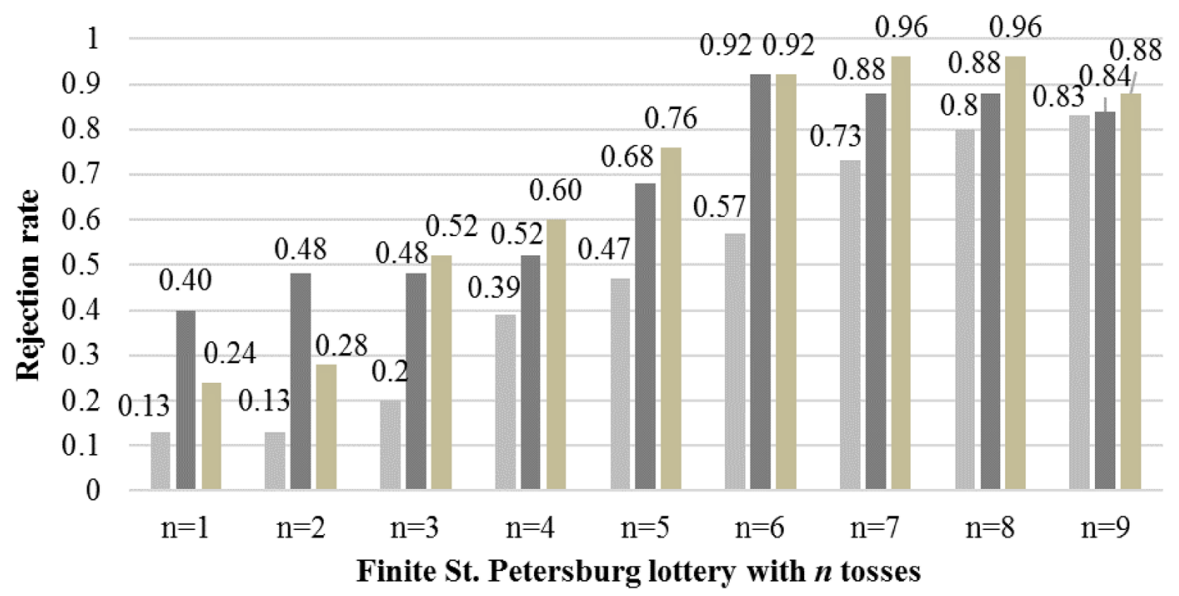

$\square$ Cox et al. (2009) - monetary gains

Base Waiting Time: 10 minutes

Base Waiting Time: 45 minutes

Fig. 2 Comparison of rejecting St. Petersburg lotteries of money risk-averse and time risk-seeking subjects

who chooses option A in rows one through four and then switches to option B is noted in column five.

We observe 27 out of 36 subjects $(75.00 \%$; 95\% CI [0.58, 0.88]) who made choices consistent with risk-seeking behavior. Therefore, we conclude that the vast majority of subjects exhibit risk-seeking behavior when making decisions about stochastic waiting time ( $p=0.002$, binomial test).

\subsubsection{St. Petersburg game}

Data from elicitation of risk attitudes over waiting time suggest that the majority of subjects are risk-seeking and therefore would play all of the offered St. Petersburg lotteries for waiting time. The expected value of the offered gambles on waiting times is equal to the base waiting time. Therefore, a risk-seeking individual would choose to participate in all offered gambles. Data from the St. Petersburg game with waiting times as prizes show that while individuals do participate in the gambles for small reductions of the base waiting time, they do not for higher possible reductions of the base waiting time. Furthermore, decision patterns are similar to those found in the real-payoff experiment with St. Petersburg lotteries with positive money prizes (Cox et al. 2009) and to the Experiment 1 reported above, with negative money prizes (Fig. 2).

With increasing $n$, subjects exerted decreasing willingness to play. Within the 10-min condition (dark grey bars), the correlation between $n$ and the number of subjects rejecting is $r_{\text {Spearman }}=0.880, p=0.002$, whereas the $45-\mathrm{min}$ condition (ocher bars) yields an $r$ of 953, $p<0.001$. Like in Experiment 1 on monetary losses, both waiting time conditions show a pronounced correlation with the results reported by Cox et al. (2009) on positive monetary prizes $\left(r_{\text {Pearson, } 10 \text { min }}=0.922\right.$, 
$\left.p<0.001, r_{\text {Pearson, } 45 \min }=0.937, p<0.001\right)$. Again, we were hardly able to observe risk-seeking-conform behavior at the individual level (increasing willingness to play with increasing $n)$, either in the 10 -min condition $(3 / 25, p<0.001$ in a binomial test) nor in the 45 -min condition $(1 / 25, p<0.001$ in a binomial test).

In the treatment with a base waiting time of $10 \mathrm{~min}, 2$ of the 25 participants chose to never play the game, while the rest mostly started by playing the first game, but switched to answering 'no' at some $n$. None of the participants chose to play all offered games. The data from the treatment with a base waiting time of $45 \mathrm{~min}$ yielded similar results. Fewer subjects were willing to play lotteries with high reductions of the base waiting time $(n \geq 7)$ than observed in the 10 -min treatment. However, the difference is not meaningful, as we were not able to identify significant differences based on Fisher's exact tests: $p_{n=7}=0.609, p_{n=8}=0.609$, $p_{n=9}=1.0$.

\section{Discussion and conclusion}

The St. Petersburg paradox was initially designed to challenge expected value theory. It inspired the idea of using utilities, with decreasing marginal utility of money, rather than monetary payoffs to resolve the paradox. From that point on, economists have focused on developing theories of decision-making under risk that can accommodate risk-averse behavior as initially reported for hypothetical experiments with the infinite horizon St. Petersburg lottery. Alternative ways of modeling risk-aversion have been proposed in the literature (for a review of mathematical model attempts see, Seidl 2013). Risk-averse behavior can be modeled by nonlinear transformation of: (1) payoffs (Bernoulli 1954; Pratt 1964; Arrow 1971), (2) probabilities (Yaari 1987), or (3) both (Quiggin 1993; Tversky and Kahneman 1992). But there are versions of St. Petersburg lotteries that produce paradoxes for all of these theories if they are defined on unbounded domains (Cox and Sadiraj 2009). If, instead, the domain is bounded, then the paradox disappears. For example, if the largest credible prize offered in a St. Petersburg lottery is 35 billion euros, then the expected value of the lottery is about 35 euros and it would not be paradoxical if people were unwilling to pay large amounts to play.

Although the original infinite horizon St. Petersburg game cannot credibly be offered to anyone in a real-payoff experiment, finite versions are still of interest for elicitation of risk preferences. Real-money experiments with positive prize St. Petersburg lotteries produced data that are inconsistent with risk-neutrality but consistent with risk-aversion (Cox and Sadiraj 2009; Neugebauer 2010). Data from the first experiment in this paper implement a setting in which subjects are believed to be risk-loving. It is interesting to see that St. Petersburg lotteries elicit similar behavior with negative or positive monetary prizes. Even more strikingly, our second experiment on the St. Petersburg game, with waiting times as prizes, elicits similar patterns of behavior even though most subjects appear to be risk seekers in this domain. The payoff domain invariance of behavior in these St. Petersburg games provides a challenge for decision theory under risk. 
While the hypothesis of infinity (Brito 1975; Cowen and High 1988), associated with the original form of the game, is not directly relevant for our finite St. Petersburg games, the concern on whether participants would regard the offer of the original game as credible (Shapley 1977) remains valid. Thus, while infinity is not the problem in our games, is it possible to control whether participants regarded the offer as genuine?

If subjects would regard an offer as not credible, it is reasonable to assume that high monetary losses or the longer waiting times would not be realized and, therefore, a subject playing the lotteries with relatively large maximum number of coin tosses, $n$ would prefer participation in St. Petersburg game with negative prizes. That is not what we observe in the experiment.

Other papers argue that very small probabilities are regarded as zero (Brito 1975) or that small probabilities for high wins result in a high risk for the decision maker (Allais 1952; Weirich 1984) with a large payment. While these arguments can explain increasing pattern of rejections for positive St. Petersburg game, they fail badly in explaining increasing pattern of rejections of participation that we observe in our data from St. Petersburg games with negative prizes. This is so as nullification of small probabilities or increasing risk for a risk-seeker (as revealed in Holt-Laury elicitation treatment in Experiment 2) make participation in the game with negative prizes more attractive as $n$ increases, so we should observe a decreasing pattern of rejections as $n$ increases, the opposite of what we see in our data, with monetary payment as well as waiting time.

In conclusion, it can be noted that various conjectures have been advanced to explain behavior with St. Petersburg lotteries. However, with the exception of riskaversion, none of the conjectures can explain what is observed in our experiments with decisions for real monetary and waiting time outcomes. Nevertheless, while risk-aversion can explain behavior in our St. Petersburg game, such risk-aversion in the waiting time experiments conflicts with risk-seeking attitudes elicited by the Holt-Laury procedure.

As our results are both, surprising and relevant to business research, future researchers should empirically reevaluate models that have been proposed to explain the behavior observed in the St. Petersburg paradox relying on experiments involving real economic consequences. Likewise, other domains of seemingly irrational decision-making would benefit from experiments drawing on real consequences involving losses. For example, in case of violations of rational choice such as context-dependent choice (Cox et al. 2014), researchers recently discovered that some choice anomalies decrease (e.g., the compromise effect, Lichters et al. 2015) while others increase (e.g., the attraction effect, Lichters et al. 2017 ) in magnitude with the introduction of economic consequences instead of mere hypothetical choices.

Open Access This article is distributed under the terms of the Creative Commons Attribution 4.0 International License (http://creativecommons.org/licenses/by/4.0/), which permits unrestricted use, distribution, and reproduction in any medium, provided you give appropriate credit to the original author(s) and the source, provide a link to the Creative Commons license, and indicate if changes were made. 


\section{Appendix: St. Petersburg game and loss aversion}

Let the utility over outcomes be given as

$$
v(x)=\left\{\begin{array}{ll}
u(x), & x>0 \\
0, & x=0 \\
-\lambda u(-x), & x<0
\end{array}\right\}
$$

where $\lambda \geq 1$. For the purpose of this paper we assume the functional is linear in probabilities.

Result 1: If $\lambda \geq 1$ then for all finite $n$ acceptance of participation in one game implies rejection in its sign-mirror game.

Proof Let $\mathrm{S}_{n}$ and $\mathrm{P}_{n}$ denote participation in the finite St. Petersburg game with negative and positive prizes that offer up to $n$ coin flips. The value of participating in the $n$-finite version of the St. Petersburg game, $P_{n}$ with positive prizes is

$$
\begin{aligned}
V\left(P_{n}\right) & =\sum_{i=1 . . n} \frac{1}{2^{i}} u\left(2^{i}-n\right)+\frac{1}{2^{n}} u(-n) \\
& =\sum_{i>\ln n / \ln 2}^{n} \frac{1}{2^{i}} u\left(2^{i}-n\right)-\lambda\left(\sum_{j<\ln n / \ln 2^{j}} \frac{1}{2^{j}} u\left(n-2^{j}\right)+\frac{1}{2^{n}} u(n)\right)
\end{aligned}
$$

whereas the value of participating in $n$-finite version of the St. Petersburg game, $\mathrm{S}_{n}$ with negative prizes is

$$
\begin{aligned}
V\left(S_{n}\right) & =\sum_{i=1 . . n} \frac{1}{2^{i}} u\left(n-2^{i}\right)+\frac{1}{2^{n}} u(n) \\
& =-\lambda \sum_{i>\ln n / \ln 2^{2}} \frac{1}{2^{i}} u\left(2^{i}-n\right)+\sum_{j<\ln n / \ln 2^{j}} \frac{1}{2^{j}} u\left(n-2^{j}\right)+\frac{1}{2^{n}} u(n)
\end{aligned}
$$

It can be verified that

$$
V\left(P_{n}\right)+\lambda V\left(S_{n}\right)=\left(1-\lambda^{2}\right) \sum_{i>\ln n / \ln 2}^{n} \frac{1}{2^{i}} u\left(2^{i}-n\right)
$$

For $\lambda \geq 1$, the left hand side of the last equation is non-positive and therefore acceptance of $S_{n}$ requires rejection of $P_{n}$; similarly acceptance of $P_{n}$ requires rejection of $S_{n}$ (Fig. 3, Table 5). 


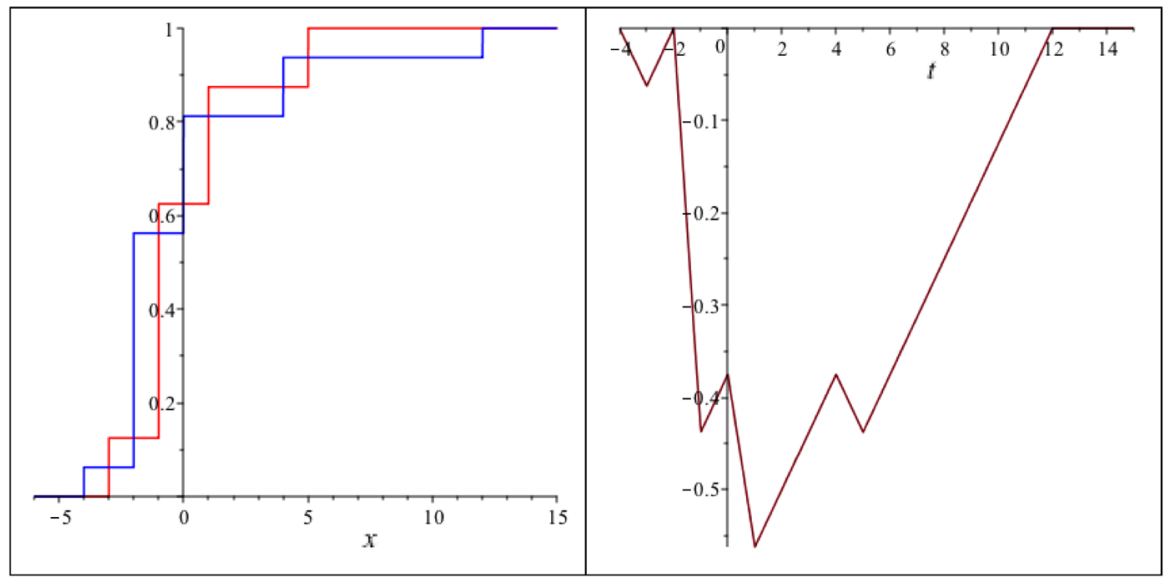

Fig. $3 S_{3} s$-order stochastic dominant over $\mathrm{S}_{4}$. On the left: cumulative distributions of $\mathrm{S}_{3}$ (red) and $\mathrm{S}_{4}$ (blue); on the right: $\int_{-4}^{x}\left[S_{3}(z)-S_{4}(z)\right] \mathrm{d} x$

Table 5 Illustration of valuations of St. Petersburg games with linearity in probabilities and power function of payoffs

$$
\begin{gathered}
u(x)=\frac{1}{1-r} x^{1-r}, \quad x>0 \\
=-\frac{\lambda}{1-r}(-x)^{1-r}, \quad x<0
\end{gathered}
$$

$n \quad$ St. Petersburg game with payments $-2^{n}$

\begin{tabular}{llllll}
\hline $\begin{array}{l}\text { EV } \\
r=0, \lambda=1\end{array}$ & $\begin{array}{l}\text { Diminish. } \\
\text { sensitivity } \\
r=0.5, \lambda=1\end{array}$ & $\begin{array}{l}\text { Loss } \\
\text { aversion } \\
r=0.5, \lambda=2\end{array}$ & $\begin{array}{l}\text { EV } \\
r=0,\end{array}$ & $\begin{array}{l}\text { Diminish. } \\
\text { sensitivity } \\
r=0.5, \lambda=1\end{array}$ & $\begin{array}{l}\text { Loss } \\
\text { aversion } \\
r=0.5, \\
\lambda=2\end{array}$ \\
\hline 0 & 0 & -1 & 0.25 & 0.25 & -0.61 \\
0 & 0 & -0.71 & 0.25 & 0.59 & -0.07 \\
0 & 0.37 & -0.69 & 0.25 & -0.15 & -1.43 \\
0 & 0.73 & -0.20 & 0.25 & -0.36 & -1.93 \\
0 & 1.20 & 0.03 & 0.25 & -1.03 & -3.26 \\
0 & 1.48 & 0.17 & 0.25 & -1.34 & -4.01 \\
0 & 1.80 & 0.45 & 0.25 & -1.67 & -4.72 \\
0 & 2.28 & 1.10 & 0.25 & -2.07 & -5.46 \\
0 & 2.78 & 1.54 & 0.25 & -2.67 & -6.58
\end{tabular}

\section{References}

Abdellaoui, Mohammed, and Emmanuel Kemel. 2014. Eliciting prospect theory when consequences are measured in time units: “Time Is Not Money". Management Science 60 (7): 1844-1859. https://doi. org/10.1287/mnsc.2013.1829.

Allais, Maurice. 1952. Le comportement de l'homme rationnel devant le risque: Critique des postulats et axiomes de l'école américaine. Econometrica 21 (4): 503-546. 
Arrow, K.J. 1971. Essays in the theory of risk-bearing. Chicago, IL: Markham Pub. Co.

Åstebro, Thomas, José Mata, and Luís Santos-Pinto. 2015. Skewness seeking: Risk loving, optimism or overweighting of small probabilities? Theory and Decision 78 (2): 189-208. https://doi.org/10.1007/ s11238-014-9417-4.

Aumann, Robert J. 1977. The St Petersburg paradox: A discussion of some recent comments. Journal of Economic Theory 14 (2): 443-445.

Bernoulli, Daniel. 1954. Exposition of a New Theory on the Measurement of Risk. Econometrica 22 (1): 23-36.

Blavatskyy, Pavlo R. 2005. Back to the St. Petersburg Paradox? Management Science 51 (4): 677-678. https://doi.org/10.1287/mnsc.1040.0352.

Brito, Dagobert L. 1975. Becker's theory of the allocation of time and the St. Petersburg paradox. Journal of Economic Theory 10 (1): 123-126.

Camerer, Colin. 2005. Three Cheers-Psychological, Theoretical, Empirical-for Loss Aversion. Journal of Marketing Research 42 (2): 129-133. https://doi.org/10.1509/jmkr.42.2.129.62286.

Camerer, Colin F., and Robin M. Hogarth. 1999. The effects of financial incentives in experiments: A review and capital-labor-production framework. Journal of Risk and Uncertainty 19 (1-3): 7-42. https://doi.org/10.1023/A:1007850605129.

Chechile, Richard A., and Daniel H. Barch. 2013. Using logarithmic derivative functions for assessing the risky weighting function for binary gambles. Journal of Mathematical Psychology 57 (1-2): 15-28. https://doi.org/10.1016/j.jmp.2013.03.001.

Cowen, Tyler, and Jack High. 1988. Time, bounded utility, and the St. Petersburg paradox. Theory and Decision 25 (3): 219-223. https://doi.org/10.1007/BF00133163.

Cox, James C., and Vjollca Sadiraj. 2009. Risky Decisions in the Large and in the Small. In Risk aversion in experiments, ed. James C. Cox and G.W. Harrison, 9-40. Bradford: Emerald Group Publishing.

Cox, James C., Vjollca Sadiraj, and Ulrich Schmidt. 2014. Asymmetrically dominated choice problems, the isolation hypothesis and random incentive mechanisms. PLoS One 9 (3): e90742. https://doi.org/ 10.1371/journal.pone.0090742.

Cox, James C., Vjollca Sadiraj, and Bodo Vogt. 2009. On the empirical relevance of St. Petersburg lotteries. Economics Bulletin 29 (1): 214-220.

Durand, David. 1957. Growth Stocks and the Petersburg Paradox. The Journal of Finance 12 (3): 348-363. https://doi.org/10.1111/j.1540-6261.1957.tb04143.x.

Etchart-Vincent, N., and O. l'Haridon. 2011. Monetary incentives in the loss domain and behavior toward risk: An experimental comparison of three reward schemes including real losses. Journal of Risk and Uncertainty 42 (1): 61-83. https://doi.org/10.1007/s11166-010-9110-0.

Farber, Henry S. 2008. Reference-Dependent Preferences and Labor Supply: The Case of New York City Taxi Drivers. American Economic Review 98 (3): 1069-1082. https://doi.org/10.1257/aer.98.3.1069.

Hacking, Ian. 1980. Strange Expectations. Philosophy of Science 47 (4): 562-567. https://doi.org/10. $1086 / 288956$.

Holt, Charles A., and Susan K. Laury. 2002. Risk aversion and incentive effects. The American Economic Review 92 (5): 1644-1655. https://doi.org/10.1257/000282802762024700.

Holt, Charles A., and Susan K. Laury. 2005. Risk aversion and incentive effects: New data without order effects. The American Economic Review 95 (3): 902-904.

Kahneman, Daniel, and Amos Tversky. 1979. Prospect Theory: An Analysis of Decision under Risk. Econometrica 47 (2): 263-292. https://doi.org/10.2307/1914185.

Kahneman, Daniel, and Amos Tversky. 1984. Choices, values, and frames. American Psychologist 39 (4): 341-350. https://doi.org/10.1037/0003-066X.39.4.341.

Köszegi, Botond, and Matthew Rabin. 2007. Reference-Dependent Risk Attitudes. American Economic Review 97 (4): 1047-1073. https://doi.org/10.1257/aer.97.4.1047.

Lichters, Marcel, Paul Bengart, Marko Sarstedt, and Bodo Vogt. 2017. What really Matters in Attraction Effect Research: When Choices Have Economic Consequences. Marketing Letters 28 (1): 127-138. https://doi.org/10.1007/s11002-015-9394-6.

Lichters, Marcel, Claudia Brunnlieb, Gideon Nave, Marko Sarstedt, and Bodo Vogt. 2016. The Influence of Serotonin Deficiency on Choice Deferral and the Compromise Effect. Journal of Marketing Research 53 (2): 183-198. https://doi.org/10.1509/jmr.14.0482.

Lichters, Marcel, Marko Sarstedt, and Bodo Vogt. 2015. On the practical Relevance of the Attraction Effect: A cautionary Note and Guidelines for Context Effect Experiments. AMS Review 5 (1-2): 1-19. https://doi.org/10.1007/s13162-015-0066-8. 
Mishra, Sandeep. 2014. Decision-Making Under Risk: Integrating Perspectives From Biology, Economics, and Psychology. Personality and Social Psychology Review 18 (3): 280-307. https:// doi.org/10.1177/1088868314530517.

Mookherjee, Dilip, and Ivan Png. 1989. Optimal Auditing, Insurance, and Redistribution. The Quarterly Journal of Economics 104 (2): 399-415. https://doi.org/10.2307/2937855.

Neugebauer, Tibor. 2010. Moral Impossibility in the St Petersburg Paradox: A Literature Survey and Experimental Evidence. Luxembourg School of Finance Research Working Paper Series 10 (174): 1-43.

Pratt, John W. 1964. Risk Aversion in the Small and in the Large. Econometrica 32 (1-2): 122-136.

Quiggin, John. 1993. Generalized Expected Utility Theory: The Rank-Dependent Model. Boston: Kluwer Academic Publishers.

Real, Leslie A. 1980. Fitness, Uncertainty, and the Role of Diversification in Evolution and Behavior. The American Naturalist 115 (5): 623-638. https://doi.org/10.1086/283588.

Real, Leslie A. 1996. Paradox, Performance, and the Architecture of Decision-Making in Animals. American Zoologist 36 (4): 518-529. https://doi.org/10.1093/icb/36.4.518.

Rieger, Marc O., and Mei Wang. 2006. Cumulative prospect theory and the St. Petersburg paradox. Economic Theory 28 (3): 665-679. https://doi.org/10.1007/s00199-005-0641-6.

Rieger, Marc O., Mei Wang, and Thorsten Hens. 2015. Risk Preferences Around the World. Management Science 61 (3): 637-648. https://doi.org/10.1287/mnsc.2013.1869.

Rosenboim, Mosi, and Tal Shavit. 2012. Whose money is it anyway? Using prepaid incentives in experimental economics to create a natural environment. Experimental Economics 15 (1): 145-157. https://doi.org/10.1007/s10683-011-9294-4.

Rubinstein, Mark. 2002. Markowitz's "Portfolio Selection": A Fifty-Year Retrospective. The Journal of Finance 57 (3): 1041-1045. https://doi.org/10.1111/1540-6261.00453.

Samuelson, Paul A. 1960. The St. Petersburg paradox as a divergent double limit. International Economic Review 1 (1): 31-37.

Samuelson, Paul A. 1977. St. Petersburg paradoxes: Defanged, dissected, and historically described. Journal of Economic Literature 15 (1): 24-55.

Scholer, Abigail A., Xi Zou, Kentaro Fujita, Steven J. Stroessner, and E.T. Higgins. 2010. When risk seeking becomes a motivational necessity. Journal of Personality and Social Psychology 99 (2): 215-231. https://doi.org/10.1037/a0019715.

Seidl, Christian. 2013. The St. Petersburg Paradox at 300. Journal of Risk and Uncertainty 46 (3): 247-264. https://doi.org/10.1007/s11166-013-9165-9.

Shapley, Lloyd S. 1977. The St. Petersburg paradox: A con games? Journal of Economic Theory 14 (2): 439-442. https://doi.org/10.1016/0022-0531(77)90142-9.

Shrader-Frechette, Kristin. 1985. Technological risk and small probabilities. Journal of Business Ethics 4 (6): 431-445. https://doi.org/10.1007/BF00382604.

Székely, Gábor J., and Donald S.P. Richards. 2004. The St. Petersburg Paradox and the Crash of High-Tech Stocks in 2000. The American Statistician 58 (3): 225-231. https://doi.org/10.1198/000313004x1440.

Takayasu, Hideki. 2010. How to Avoid Fragility of Financial Systems: Lessons from the Financial Crisis and St. Petersburg Paradox. In Econophysics Approaches to Large-Scale Business Data and Financial Crisis: Proceedings of Tokyo Tech-Hitotsubashi Interdisciplinary Conference + APFA7, Misako Takayasu, Tsutomu Watanabe, and Hideki Takayasu, eds. 1. Aufl., 197-207. Berlin: Springer Japan.

Thaler, Richard H., and Eric J. Johnson. 1990. Gambling with the house money and trying to break even: The effects of prior outcomes on risky choice. Management Science 36 (6): 643-660. https://doi.org/ 10.1287/mnsc.36.6.643.

Tversky, Amos, and Daniel Kahneman. 1992. Advances in prospect theory: Cumulative representation of uncertainty. Journal of Risk and Uncertainty 5 (4): 297-323. https://doi.org/10.1007/BF00122574.

Wang, Charles X., Scott Webster, and Nallan C. Suresh. 2009. Would a risk-averse newsvendor order less at a higher selling price? European Journal of Operational Research 196 (2): 544-553. https://doi. org/10.1016/j.ejor.2008.04.002.

Weirich, Paul. 1984. The St. Petersburg gamble and risk. Theory and Decision 17 (2): 193-202. https:// doi.org/10.1007/bf00160983.

Yaari, Menahem E. 1987. The Dual Theory of choice under risk. Econometrica 55 (1): 95-115.

Publisher's Note Springer Nature remains neutral with regard to jurisdictional claims in published maps and institutional affiliations. 